\title{
Effects of yeast culture on broiler growth performance, nutrient digestibility and caecal microbiota
}

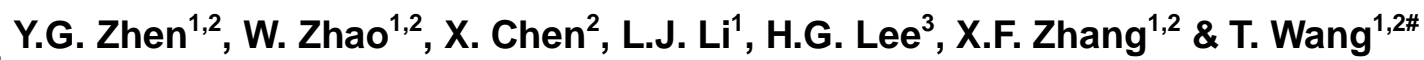 \\ ${ }^{1}$ College of Animal Science and Technology, Jilin Agricultural University, Changchun 130118, P.R.China \\ 2 JLAU-Borui Dairy Science and Technology R\&D Centre of Jilin Agricultural University, Changchun 130118, P.R. China \\ ${ }^{3}$ College of Animal Bioscience and Technology, Konkuk University, Seoul 143-701, Republic of Korea
}

(Received 25 August 2018; Accepted 21 November; First published online 8 March 2019)

\author{
Copyright resides with the authors in terms of the Creative Commons Attribution 4.0 South African Licence. \\ See: $\mathrm{http}: / /$ creativecommons. org/licenses/by/4.0/za \\ Condition of use: The user may copy, distribute, transmit and adapt the work, but must recognise the authors and \\ the South African Journal of Animal Science.
}

\begin{abstract}
This study was conducted to evaluate the effects of yeast culture (YC) supplementation on the growth performance, apparent nutrient digestibility and caecal microflora of broiler chickens. A total of 360 one-day-old Arbor Acres broiler chickens were randomly assigned to six dietary treatments containing $0.2 \%$, $0.4 \%, 0.6 \%, 0.8 \%$ and $1 \%$ YC. The experiment lasted for 42 days. Diet and faecal samples were collected for analysis of dry matter, crude protein, ether extract, calcium and phosphorus. Caecal microbiota on days 21 and 42 were measured using polymerase chain reaction-denaturing gradient gel electrophoresis (PCR-DGGE) and real-time PCR. Dietary supplementation with YC did not affect feed intake. On day 42 , the $0.8 \%$ YC group showed optimal growth and feed efficiency, as well as higher levels of apparent digestibility of ether extract, calcium and phosphorus. On day 21 , both $0.8 \%$ and $1 \%$ YC groups exhibited a significant increase in Ruminococcus, Propionibacterium clostridiales, and Bifidobacterium density. The density of Bacteroides in the YC groups was significantly higher than that of the control group. On day 42, the densities of Bacteroides, Sphingomonas and Bifidobacterium were higher in the $0.8 \%$ YC group, whereas a significant decrease was observed in the number of Enterobacteriaceae. These results serve as evidence that dietary supplementation with $0.8 \%$ YC not only moderately optimized the feed efficiency and the apparent digestibility of ether extract, calcium and phosphorus, but also positively influenced the caecal bacterial density and diversity in broiler chickens.
\end{abstract}

Keywords: Arbor Acres broiler, caecal microflora, yeast culture supplementation

\#Corresponding author: cagewang@163.com

\section{Introduction}

Yeast products have been used as probiotics in poultry and swine feed for more than 100 years (Reisinger et al., 2012). These can improve the growth performance and immune function of broiler chickens (Haldar et al., 2011; Abdelrahman, 2013). The addition of yeast culture (YC) (0.3\%) to diets containing dry fat not only improves the growth performance of broilers, but also positively affects the carcass characteristics by reducing the abdominal fat (Abdelrahman, 2013). Studies have indicated that yeast single-cell protein can positively improve the performance of broilers (Chand et al., 2014). In addition, the yeast-derived carbohydrate fraction can effectively enhance production performance, gut histomorphology and nutrient utilization of broilers during the starter phase (Sultan et al., 2015). Intestinal bacteria play an important role in animal health and growth, and beneficial microbiota inhibit the colonization of pathogenic bacteria. The microbial composition in the host reflects the coevolution of microorganisms with their animal host and the host's diet (Farthing, 1985). The site of bacterial fermentation in birds is mainly the caeca (Johansen et al., 2006). Yeast culture residues have significant effects on coliform in the caecum of broilers compared with lasalocid or bacitracin (Swinkels et al., 2006).

In this study, the authors hypothesized that dietary supplementation with YC would modify the feed efficiency and influence the caecal bacterial density and diversity in broiler chickens. Therefore, the growth performance, apparent nutrient digestibility, and caecal microflora were investigated in broiler chickens fed with various levels of $\mathrm{YC}$ for 21 and 42 days. 


\section{Materials and Methods}

Yeast cultures were developed at the JLAU-Borui Dairy Science and Technology R\&D Centre of Jilin Agricultural University (Changchun, China). Briefly, Saccharomyces cerevisiae was aerobically cultured in molasses medium (carbon source) in a $10 \mathrm{~L}$ fermenter and then transferred into a $50 \mathrm{~L}$ fermenter and incubated anaerobically for 24 hours. Papain was added to induce cell wall breakage, and fermentation was continued for 36 hours. When the bacterial dry weight reached $48.45 \mathrm{~g} / \mathrm{L}$, the yeast cell wall breakage rate was 55.5\%, and YC dry weight was $226 \mathrm{~g} / \mathrm{L}$. The fully fermented YC contained yeast and various metabolites such as amino acids (e.g. glycine), inositol, organic acids and mannose.

A total of 360 Arbor Acres broiler chickens (one-day-old, average weight $45.0 \pm 3.2 \mathrm{~g}$ ) were divided into six groups and fed diets containing $0 \%, 0.2 \%, 0.4 \%, 0.6 \%, 0.8 \%$ or $1 \%$ YC. Each group comprised 6 replicate pens with 10 birds per pen. Each pen was $0.9 \mathrm{~m}^{2}$ in size and equipped with a clean plastic net and nipple drinker. Feed (Table 1) and water were provided ad libitum. Feed intake was recorded weekly. Lighting and temperature were controlled according to the standard recommendations for broilers (NY/T2666-2014, 2015). The lighting conditions included 23 hours for the first three days, which were then gradually decreased to that of natural daylight. The room temperature was maintained within the range of $32{ }^{\circ} \mathrm{C}$ to $34^{\circ} \mathrm{C}$ during the first six days and then gradually decreased by $2{ }^{\circ} \mathrm{C} /$ week to a final room temperature range of $22{ }^{\circ} \mathrm{C}$ to $24^{\circ} \mathrm{C}$. Vaccines against Newcastle disease and infectious bursal disease were administered on days 7 and 21 and again on days 14 and 28, respectively. The feeding trials were conducted for 21 and 42 days. The experimental procedure was approved by the Institutional Animal Care and Use Committee of Jilin Agricultural University.

Table 1 Ingredients and chemical compositions of the basal diets (\% dry matter)

\begin{tabular}{lcc}
\hline Ingredients & $\mathbf{1}$ - 21 days & 22 - 42 days \\
\hline Corn & 52.07 & 55.57 \\
Soybean & 35.50 & 34.00 \\
Fish meal & 5.00 & 3.60 \\
Soybean oil & 4.00 & 3.5 \\
Phosphate & 1.00 & 0.70 \\
Limestone & 1.00 & 1.20 \\
Salt & 0.30 & 0.30 \\
Lysine & 0.04 & 0.04 \\
Methionine & 0.09 & 0.09 \\
Additive & 1.00 & 1.00 \\
Total & 100 & 100 \\
Nutritive value & & \\
Metabolizable energy (MJ/kg) & 12.75 & 12.72 \\
Crude protein (\%) & 20.72 & 19.61 \\
Calcium (\%) & 0.91 & 0.87 \\
Total phosphorus (\%) & 0.68 & 0.58 \\
Available phosphorus (\%) & 0.45 & 0.36 \\
Lysine (\%) & 1.35 & 1.25 \\
Methionine (\%) & 0.46 & 0.43
\end{tabular}

${ }^{1}$ Supplied per kilogram of diet: vitamin $\mathrm{A}, 5000 \mathrm{IU}$; vitamin $\mathrm{D}_{3}, 1500 \mathrm{IU}$; vitamin $\mathrm{E}, 15 \mathrm{IU}$; menadione, $0.8 \mathrm{mg}$; vitamin $\mathrm{B}_{12}, 0.01 \mathrm{mg}$; folic acid, $0.5 \mathrm{mg}$; nicotinic acid, $50 \mathrm{mg}$; biotin, $0.1 \mathrm{mg}$; pantothenic acid, $8 \mathrm{mg}$; pyridoxine, $2.2 \mathrm{mg}$; riboflavin, $4.4 \mathrm{mg}$; thiamine mononitrate, $1.6 \mathrm{mg}$ Mineral premix contained per kilogram of diet: Fe, 80 g; Cu, $6 \mathrm{mg}$; Mn, $100 \mathrm{mg} ; \mathrm{Zn}, 80 \mathrm{mg} ; \mathrm{I}, 0.4 \mathrm{mg}$; Se, $0.2 \mathrm{mg}$ 
During the experimental period, the broiler chickens were weighed weekly in the morning to determine average daily gain (ADG), average daily feed intake (ADFI) and feed to gain ratio (F : G) from days 8 to 21 and from days 22 to 42 . For apparent total tract digestibility, a total collection method was used. On day 35 , one bird per pen was fed in a metabolism cage. Faeces collection was initiated on day 40 before feeding the birds. Excreta from each cage were collected daily into sterile plastic bags, $10 \% \mathrm{H}_{2} \mathrm{SO}_{4}$ was then added, and the bags were stored at $-20^{\circ} \mathrm{C}$. The faecal samples collected during the three days were pooled and oven-dried at $65{ }^{\circ} \mathrm{C}$ for 72 hours, then ground through a 1-mm screen. Diet and faecal samples were analysed for dry matter (DM), crude protein (CP), crude fat (EE), calcium (Ca) and phosphorus (P). CP was determined using the Kjeldahl method. Crude fibre was obtained by using a Soxhlet extraction unit. Ca was analysed with an atomic absorption spectrophotometer (Analyst $800 \mathrm{PE}$, Perkin Elmer Inc., Waltham, MA, USA). P levels after pre-treatment were determined using ammonium-vanadium-molybdate, similar to that for $\mathrm{Ca}$, and were estimated spectrophotometrically (UV-visible spectrophotometer, Shimadzu, Tokyo, Japan) at a wavelength of $420 \mathrm{~nm}$ (AOAC International, 2005). Apparent nutrient digestibility was calculated as follows:

Apparent total tract nutrient digestibility $(\%)=\{1-[(A \times B) /(C \times D)]\} \times 100$,

where: $\quad A$ is the nutrient content of the faecal sample

$\mathrm{B}$ is the weight of the faecal sample (\% DM)

$\mathrm{C}$ is the nutrient content of the feed

$\mathrm{D}$ is the weight of the feed (\% DM)

On days 21 and 42, the birds were weighed and slaughtered. One side of the caecum was fastened with a string and stored at $-20^{\circ} \mathrm{C}$ until DNA extraction.

DNA was extracted from the caecum digesta and each group comprised six DNA samples. The variable V3 region of the bacterial $16 S$ rDNA gene sequence was amplified using primers $341 \mathrm{f}$ and $518 \mathrm{r}$ (Yu \& Morrison, 2004). The PCR mixture consisted of $1 \mu \mathrm{L}$ of the DNA template, $1 \mu \mathrm{L}$ of the forward primer $(10 \mu \mathrm{M})$, $1 \mu \mathrm{L}$ of the reverse primer $(10 \mu \mathrm{M}), 12.5 \mu \mathrm{L}$ of a $2 \times$ TaqMasterMix, and $9.5 \mu \mathrm{L}$ of $\mathrm{ddH}_{2} \mathrm{O}$. The PCR conditions consisted of $95^{\circ} \mathrm{C}$ for $2 \mathrm{~min}$, followed by 35 cycles at $95^{\circ} \mathrm{C}$ for 30 seconds, $60^{\circ} \mathrm{C}$ for 30 seconds, $72{ }^{\circ} \mathrm{C}$ for 30 seconds, and a final $72^{\circ} \mathrm{C}$ for $5 \mathrm{~min}$. All PCR products were electrophoresed in $1 \%(\mathrm{~W} / \mathrm{V})$ agarose gels to assess the size and quality of the bands. Denaturing gradient gel electrophoresis (DGGE) was performed with a D Code universal mutation detection system (Bio-Rad Laboratories Inc., Hercules, CA). A total of six PCR products from each treatment were pooled, and $20 \mu \mathrm{L}$ of the mixture were loaded onto an $8 \%(\mathrm{w} / \mathrm{v})$ polyacrylamide gel (acrylamide : bisacrylamide $=37.5: 1$ ), and the denaturant gradient range was $35 \%-55 \%$. After electrophoresis, the gel was scanned and analysed using Quantity One for UPGMA. Prominent bands in the gel were excised and re-amplified. The amplified PCR products were cloned and sequenced (Sangong Biotech Co. Ltd., Shanghai, China). The sequences of DGGE bands were compared with those in GenBank using BLAST.

Real-time PCR was performed using a StepOnePlus ${ }^{\mathrm{TM}}$ real-time PCR system (Thermo Fisher Scientific, Waltham, MA, USA). The primers were designed and synthesized by Sangong Biotech Co. Ltd. (Shanghai, China) (Table 2). Then, plasmid DNA was extracted from the clone, and its concentration was determined using NanoDrop 2000 (Thermo Fisher Scientific, Waltham, MA, USA). Each RT-PCR reaction consisted of 10 $\mu \mathrm{L}$ of SYBR Premix Ex Taq (TaKaRa, Dalian, China), $0.8 \mu \mathrm{L}$ of a forward primer $(10 \mu \mathrm{M}), 0.8 \mu \mathrm{L}$ of a reverse primer $(10 \mu \mathrm{M}), 0.4 \mu \mathrm{L}$ of a ROX reference dye (50x), $2 \mu \mathrm{Lof}$ the DNA template and $6 \mu \mathrm{L}$ of $\mathrm{ddH}_{2} \mathrm{O}$. Two replicates were prepared using each DNA template. The RT-PCR conditions consisted of $95{ }^{\circ} \mathrm{C}$ for 30 seconds; followed by 40 cycles at $95{ }^{\circ} \mathrm{C}$ for 15 seconds, $60^{\circ} \mathrm{C}$ for 34 seconds, $95^{\circ} \mathrm{C}$ for 15 seconds, $60^{\circ} \mathrm{C}$ for 60 seconds, and $95^{\circ} \mathrm{C}$ for 15 seconds. Each standard plasmid was serially diluted (1:10), ranging from $1 \times 10^{2}$ to $1 \times 10^{7}$ copies to estimate its density, presuming that bacteria harbour one copy of 16S rDNA per cell (Coci et al., 2010).

Data were expressed as the mean \pm SE and subjected to general linear model (GLM) univariate ANOVA using SPSS for Windows, version 17.0 (Chicago, IL, USA). Differences among means were assessed using Duncan's multiple-range test. Production parameters were analysed with the orthogonal polynomial for linear, quadratic and cubic responses. $P$ values of $<0.05$ were considered statistically significant.

\section{Results}

No significant differences in ADFI, ADG and F : G were observed among the groups for days $8-21$ (Table 3). However, for days 22 - 42, the addition of $0.8 \%$ YC resulted in a $5.85 \%$ decrease in $F: G(P<0.05)$ relative to the control. Generally from days $8-42$, only the $0.8 \%$ YC group showed significantly lower $F: G$, suggesting better feed efficiency $(P<0.05)$. 
Table 2 Bacterial 16S rDNA targeted by real-time polymerase chain reaction

\begin{tabular}{|c|c|c|c|}
\hline Target bacterium & Primer sequences & Product size (bp) & Annealing temperature $\left({ }^{\circ} \mathrm{C}\right)$ \\
\hline \multirow{2}{*}{ Ruminococcus } & F: 5'-GGCTGCTGGCACGTATTTAG-3' & \multirow{2}{*}{191} & \multirow{2}{*}{60} \\
\hline & R: 5'-GCGTGAGCGAAGAAGTACC-3' & & \\
\hline \multirow{2}{*}{ Clostridiales } & F: 5'-GGCTGCTGGCACGTATTTAG-3' & \multirow{2}{*}{191} & \multirow{2}{*}{60} \\
\hline & R: 5'-CGCGTGAGCGAAGGAGTAT-3' & & \\
\hline \multirow{2}{*}{ Bacteroides } & F: 5'-CACGGAGTTAGCCGATCCT-3' & \multirow{2}{*}{191} & \multirow{2}{*}{60} \\
\hline & R: 5'-GAAGTCTGAACCAGCCATGC-3' & & \\
\hline \multirow{2}{*}{ Sphingomonas } & F: 5'-GGACTGGTATTGACGCTGAG-3' & \multirow{2}{*}{250} & \multirow{2}{*}{60} \\
\hline & R: 5'-ACGCTGGTAAGGTTCTGC-3' & & \\
\hline \multirow{2}{*}{ Propionibacterium } & F: 5'-ACGGAGTTAGCCGATGCTT-3' & \multirow{2}{*}{191} & \multirow{2}{*}{60} \\
\hline & R: 5'-AGACTGAACCAGCCAAGTCG-3' & & \\
\hline \multirow{2}{*}{ Bifidobacterium } & F: 5'-GGCTGCTGGCACGTAGTTAG-3' & \multirow{2}{*}{199} & \multirow{2}{*}{60} \\
\hline & R: 5'-CGCGTGAGCGAAGAGGTAT-3' & & \\
\hline \multirow{2}{*}{ Enterobacteriaceae } & F: 5'-GGCTGCTGGCACGTAGTTAG-3' & \multirow{2}{*}{171} & \multirow{2}{*}{60} \\
\hline & R: 5'-CGCGTGAGCGAAGAAGTATT-3' & & \\
\hline
\end{tabular}

Table 3 Effect of dietary yeast culture supplementation on growth performance of broilerschickens ${ }^{1}$

\begin{tabular}{|c|c|c|c|c|c|c|c|c|c|c|}
\hline & \multicolumn{7}{|c|}{ Yeast culture supplementation level (\%) ${ }^{2}$} & \multicolumn{3}{|c|}{$P$-value ${ }^{3}$} \\
\hline & 0 & 0.2 & 0.4 & 0.6 & 0.8 & 1 & SEM & $\mathbf{L}$ & Q & C \\
\hline \multicolumn{11}{|c|}{8 - 21 days } \\
\hline$A D F I^{4}, g$ & 51.2 & 50.2 & 49.5 & 51.3 & 50.2 & 50.6 & 0.36 & 0.85 & 0.86 & 0.81 \\
\hline$A D G, g$ & 38.4 & 37.6 & 37.3 & 38.9 & 38.2 & 38.3 & 0.19 & 0.55 & 0.69 & 0.28 \\
\hline$F: G$ & 1.33 & 1.32 & 1.33 & 1.32 & 1.32 & 1.32 & 0.01 & 0.57 & 0.85 & 0.92 \\
\hline \multicolumn{11}{|c|}{22 - 42 days } \\
\hline ADFI (g) & 117 & 119 & 119 & 119 & 123 & 119 & 1.06 & 0.34 & 0.59 & 0.77 \\
\hline ADG (g) & 68.4 & 73.1 & 72.9 & 71.7 & 75.3 & 71.9 & 0.82 & 0.07 & 0.08 & 0.16 \\
\hline$F: G$ & 1.71 & 1.66 & 1.66 & 1.68 & 1.61 & 1.65 & 0.01 & 0.10 & 0.21 & 0.38 \\
\hline \multicolumn{11}{|c|}{8 - 42 days } \\
\hline ADFI (g) & 90.4 & 91.4 & 90.0 & 90.7 & 91.7 & 90.1 & 0.69 & 0.99 & 0.96 & 0.99 \\
\hline ADG (g) & 56.0 & 58.3 & 57.4 & 59.0 & 60.8 & 58.1 & 0.61 & 0.12 & 0.16 & 0.26 \\
\hline$F: G$ & 1.62 & 1.57 & 1.57 & 1.54 & 1.51 & 1.55 & 0.13 & 0.05 & 0.08 & 0.14 \\
\hline
\end{tabular}

${ }^{1}$ Data were expressed as means \pm SE of six replicate pens with 10 birds per pen.

${ }^{2}$ Basal diet supplemented with $0.2 \%, 0.4 \%, 0.6 \%, 0.8 \%$ or $1 \%$ yeast culture (YC) (the dry weight was $0.452 \%, 0.904 \%$, $1.356 \%, 1.808 \%$ and $2.26 \%$ YC, respectively).

${ }^{3}$ Orthogonal contrasts: L: linear, Q: quadratic, and C: cubic effect of supplemental yeast culture

${ }^{4}$ ADG: average daily gain; ADFI: average daily feed intake; $F: G$ : feed to gain ratio

Table 4 shows that on day 21, the apparent digestibility of EE increased by $32.1 \%, 35.3 \%, 40.7 \%, 39.6 \%$ and $35.8 \%$ with $0.2 \%, 0.4 \%, 0.6 \%, 0.8 \%$ and $1 \%$ YC supplementation, respectively $(P<0.05)$. In terms of $\mathrm{Ca}$ and $\mathrm{P}$ digestibility, only the $0.8 \%$ YC group showed significant increases $(P<0.05 ; P<0.05)$. On day 42 , the highest apparent digestibility of $E E$ and $P$ was observed in the $0.8 \% Y C$ group $(P<0.05 ; P<0.05)$, whereas no significant difference in apparent digestibility of Ca was detected. 
Table 4 Effect of dietary yeast culture supplementation on apparent total tract nutrient digestibility in broilers chickens $^{1}$

\begin{tabular}{lccccccccccc}
\hline & \multicolumn{1}{c}{ Yeast culture supplementation level (\%) } & \multicolumn{3}{c}{ P-value } \\
\hline & $\mathbf{0}$ & $\mathbf{0 . 2}$ & $\mathbf{0 . 4}$ & $\mathbf{0 . 6}$ & $\mathbf{0 . 8}$ & $\mathbf{1}$ & $\mathbf{S E M}$ & $\mathbf{L}$ & $\mathbf{Q}$ & $\mathbf{C}$ \\
\hline Day 21 & & & & & & & & & & & \\
CP (\%) & 61.2 & 59.8 & 61.0 & 62.3 & 57.0 & 60.2 & 0.80 & 0.59 & 0.85 & 0.96 \\
EE (\%) & 69.0 & 79.3 & 81.2 & 84.4 & 83.8 & 81.5 & 1.59 & 0.01 & $<0.01$ & $<0.01$ \\
Ca (\%) & 58.9 & 57.5 & 62.2 & 62.7 & 67.4 & 47.3 & 1.57 & 0.82 & 0.06 & $<0.01$ \\
P (\%) & 45.2 & 49.2 & 48.8 & 51.8 & 55.8 & 50.4 & 1.26 & 0.05 & 0.10 & 0.15 \\
Day 42 & & & & & & & & & & \\
CP (\%) & 67.0 & 61.0 & 59.5 & 62.6 & 65.0 & 68.2 & 1.23 & 0.42 & 0.04 & 0.06 \\
EE (\%) & 47.0 & 54.3 & 60.7 & 66.5 & 70.3 & 58.7 & 2.27 & 0.02 & $<0.01$ & $<0.01$ \\
Ca (\%) & 64.2 & 55.1 & 57.5 & 55.0 & 52.9 & 54.9 & 1.59 & 0.09 & 0.13 & 0.26 \\
P (\%) & 40.4 & 41.4 & 42.2 & 45.6 & 48.8 & 45.7 & 1.01 & $<0.01$ & $<0.01$ & $<0.01$ \\
& & & & & & & & & & \\
\hline
\end{tabular}

${ }^{1}$ Data were expressed as means \pm SE of six replicate pens with 10 birds per pen

${ }^{2}$ Basal diet supplemented with $0.2 \%, 0.4 \%, 0.6 \%, 0.8 \%$ or $1 \%$ yeast culture (YC) (the dry weight was $0.452 \%, 0.904 \%$, $1.356 \%$, $1.808 \%$ and $2.26 \%$ YC, respectively)

${ }^{3} \mathrm{CP}$ : crude protein; EE: ether extract; Ca: calcium; P: phosphorus

Orthogonal contrasts: L: linear, Q: quadratic and C: cubic effect of supplemental yeast culture

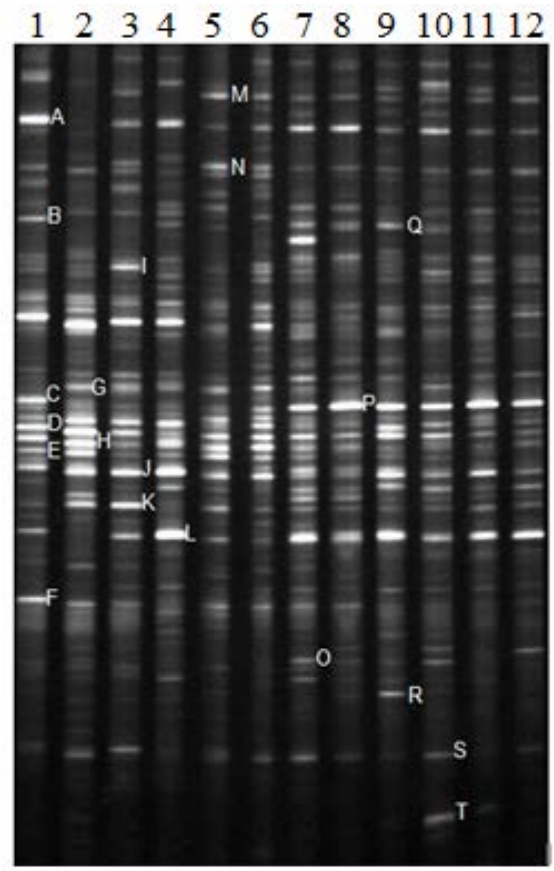

Figure 1 Caecal bacteria diversity of the $0,0.2 \%, 0.4 \%, 0.6 \%, 0.8 \%$ and $1 \%$ yeast culture groups on days 21 and 42. Lanes 1, 3, 5, 7, 9 and 11 represent the DGGE patterns of the $\mathrm{V} 3$ region of the $16 \mathrm{~S}$ rDNA from the $0 \%$, $0.2 \%, 0.4 \%, 0.6 \%, 0.8 \%$ and $1 \%$ yeast culture groups on day 21 and lanes $2,4,6,8,10$ and 12 represent the samples on day 42 , respectively

The bacterial diversity of the samples in the $0 \%, 0.2 \%, 0.4 \%, 0.6 \%, 0.8 \%$ and $1 \% \mathrm{YC}$ groups on days 21 and 42 were evaluated by DGGE (Figure 1). Band A was observed in all groups on day 42, except for the control group. Some bands (C, D, E, F, H, J, K and N) were detected in all samples, although their optical densities varied. The intensity of Band $\mathrm{F}$ on Lane 1 was markedly higher than those in the other lanes, and with increasing $\mathrm{YC}$, band intensity decreased. Bands $\mathrm{O}, \mathrm{P}, \mathrm{Q}, \mathrm{R}$ and $\mathrm{T}$ were the predominant bacteria after 
dietary supplementation with YC. The caecal bacterial flora were complex, as indicated by a higher number of similar bands among samples. However, the density of each bacterial species varied with increasing $\mathrm{YC}$ concentration.

The results of UPGMA cluster analysis of the DGGE banding patterns are shown in Figure 2. The samples were further divided into two clusters. One cluster included the $0 \%, 0.2 \%$ and $0.4 \%$ YC groups on days 21 and 42 . The other comprised the $0.6 \%, 0.8 \%$ and $1 \% \mathrm{YC}$ groups on days 21 and 42 , and the similarity of these clusters was $<0.5$. The similarity between the control and the $0.2 \%$ and $0.4 \%$ YC groups was $<0.6$ on day 21 . The similarity between the control and the $0.2 \%$ YC groups was $>0.6$, but that of the control and the $0.4 \%$ YC groups was $<0.6$ on day 42 . Compared with the control, the similarity of the $0.6 \%$, $0.8 \%$ and the $1 \%$ YC groups was the lowest. Taken together, a high level of similarity in banding pattern was observed between control and low level YC supplementation groups, whereas high levels of YC largely influenced the bacterial composition of each sample on day 42. Furthermore, no significant change in the bacterial community was observed with dietary supplementation with high-dose YC $(0.6 \%, 0.8 \%$ or $1 \%)$ on days 21 and 42 .

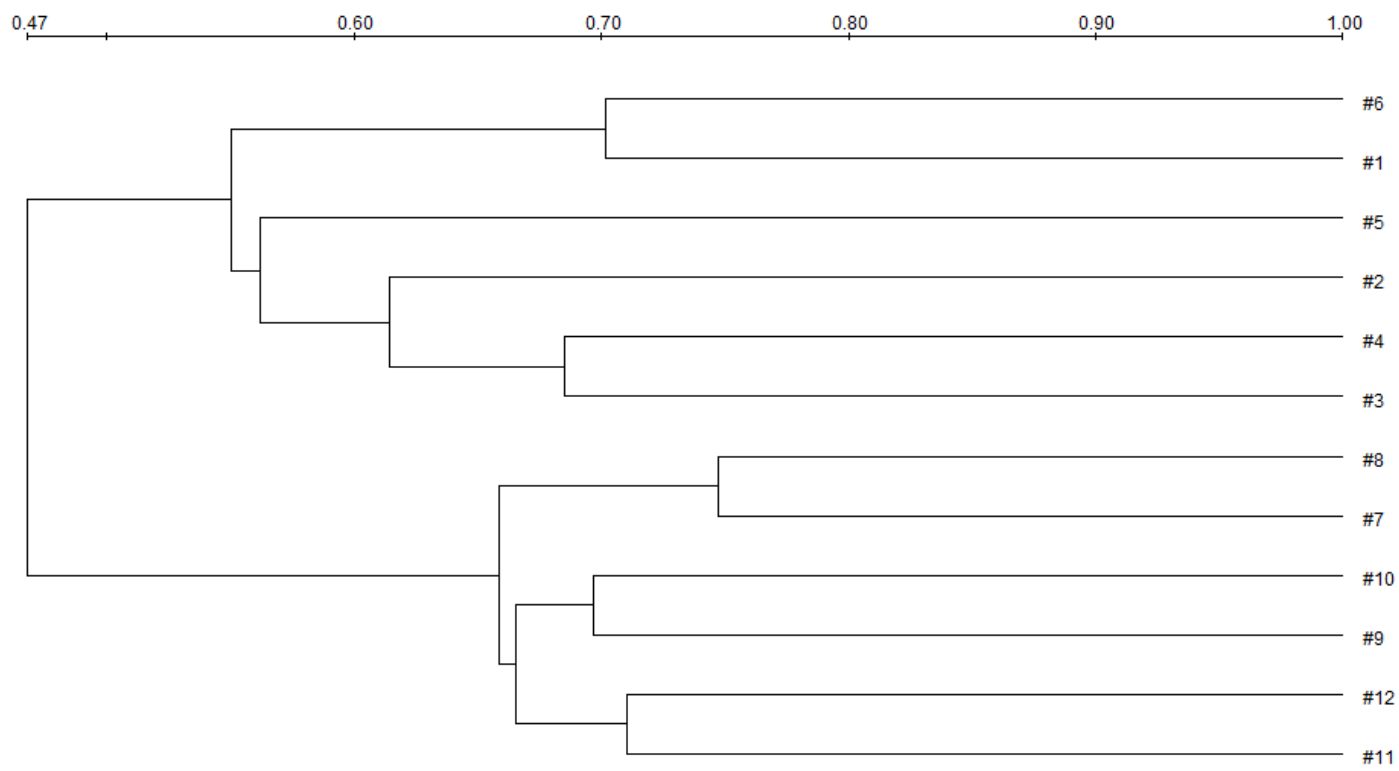

Figure 2 UPGMA cluster analysis of the DGGE banding patterns of the caecal bacteria community. 1, 3, 5, 7, 9 and 11 stands for $0,0.2 \%, 0.4 \%, 0.6 \%, 0.8 \%$ and $1 \%$ yeast culture $(\mathrm{YC})$ groups on day 21 , and 2, 4, 6, 8, 10 and 12 represent the samples on day 42 , respectively

To identify the bacterial species, the major bands in the DGGE were cloned and sequenced (Table 5). BLAST analysis indicated that the similarity of all band sequences was $\geq 98 \%$, except for bands $K$ and $Q$. The four types of bacteria in the caecum were determined to be Firmicutes, Bacteroidetes, Actinobacteria, and Proteobacteria. Alistipes spp., Rikenella spp., Firmicutes and Stomatobaculum longum gen. nov., sp. nov were the predominant bacteria with $Y C$ supplementation.

The results of real-time PCR are shown in Figures 3. Contrary to the results of PCR-DGGE, Propionibacterium and Sphingomonas were detected among the groups by real-time PCR. On day 21, the copy number of Ruminococcus and Propionibacterium in the $0.6 \%, 0.8 \%$ and $1 \%$ YC groups was significantly higher than that in the control group $(P<0.05)$. The copy number of Clostridiales in $0.8 \%$ and $1 \%$ YC groups was higher than the control $(P<0.05)$, whereas the copy number of Bacteroides in the YC group was higher than the control $(P<0.05)$. The copy number of Bifidobacterium in the $0.4 \%, 0.6 \%, 0.8 \%$ and $1 \%$ YC groups was higher than the control $(P<0.05)$. However, no significant difference in copy number of Enterobacteriaceae and Sphingomonas was observed among the groups (Figure 3a). 
Table 5 Comparison of genomic sequences in common bands and special bands by sequencing and BLAST analysis

\begin{tabular}{lccc}
\hline Band & Closest relatives found in GenBank & Similarity (\%) & GenBank Accession Number \\
\hline A & Uncultured bacterium & $100 \%$ & EU773407 \\
B & Uncultured organism & $100 \%$ & JF781977 \\
C & Ruminococcus spp. & $100 \%$ & AB262655 \\
D & Uncultured Lachnospiraceae & $100 \%$ & EF706660 \\
E & Uncultured Clostridiales & $99 \%$ & FJ440061 \\
F & Uncultured Bacteroides sp. & $98 \%$ & AJ518876 \\
G & Ruminococcus sp. & $98 \%$ & LN881607 \\
H & Uncultured bacterium & $100 \%$ & EF025273 \\
I & Uncultured Firmicute & $98 \%$ & GU958479 \\
J & Uncultured Lachnospiraceae & $99 \%$ & EF705983 \\
K & Uncultured Bifidobacterium & $96 \%$ & FJ518688 \\
L & Propionibacterium & $99 \%$ & KR232873 \\
M & Sphingomonas sp. & $100 \%$ & LC025519 \\
N & Uncultured Enterobacteriaceae & $100 \%$ & JQ683550 \\
O & Firmicutebacterium & $99 \%$ & AB262657 \\
P & Uncultured Rikenellas sp. & $100 \%$ & KF509772 \\
Q & Alistipes sp. & $95 \%$ & FJ572413 \\
R & Stomatobaculum longum gen. nov.,sp. nov & $100 \%$ & NR-117792 \\
S & Uncultured bacterium & $99 \%$ & EF521994 \\
T & Uncultured bacterium & $98 \%$ & HE611139 \\
\hline
\end{tabular}

On day 42 , the copy number of Ruminococcus in the $1 \%$ YC group was significantly higher than the control $(P<0.05)$. The copy number of Bacteroides and Bifidobacterium in the $0.4 \%, 0.6 \%$ and $0.8 \%$ YC groups was higher than the control $(P<0.05)$, whereas the copy number of Enterobacteriaceae was lower $(P$ $<0.05)$. The copy number of Sphingomonas in the $0.8 \%$ YC group was higher than the control $(P<0.05)$. The copy number of Clostridiales and Propionibacterium did not significantly differ among groups (Figure 3b).

\section{Discussion}

The present study showed that $Y C$ did not result in significant differences in feed intake or growth performance of broilers during the starter period (days 8 to 21). Zhang et al. (2005) reported a higher body weight gain in yeast cell wall-fed birds compared with the controls from weeks 0 to 5 , although no significant difference in feed intake was observed. Reisinger et al. (2012) indicated that body weight and daily weight gain were higher in birds receiving $0.1 \%$ yeast derivative compared with controls on days $14-35$ and days $1-35$. The present study showed that supplementation with $0.8 \%$ YC increased ADG and decreased F : G. However, the effect of $1.0 \% \mathrm{YC}$ was not as significant as that of $0.8 \% \mathrm{YC}$. Under low stress or disease-free conditions, the immune response of broilers is minimal and in the present study, a suitable level of $Y C$ was more effective in improving performance because there was no stress, viral disease, or endotoxin effects on the broilers. However, supplementation with higher amounts of YC might induce the broilers to develop immune tolerance, which may lead to wastage of energy and nutrients, thereby suppressing their growth. For example, nursery pigs fed with $5 \mathrm{~g} / \mathrm{kg}$ of $Y C$ showed higher growth performance than those supplemented with $10 \mathrm{~g} / \mathrm{kg}$ or 20 $\mathrm{g} / \mathrm{kg}$ YC (Shen et al., 2009). For broilers, $2.5 \mathrm{~g} / \mathrm{kg} \mathrm{YC}$ was the most effective dose, and their growth performance did not increase with higher YC supply (Gao et al., 2008). Nonetheless, the relationship between growth performance and $\mathrm{YC}$ concentration requires further investigation. 
a.

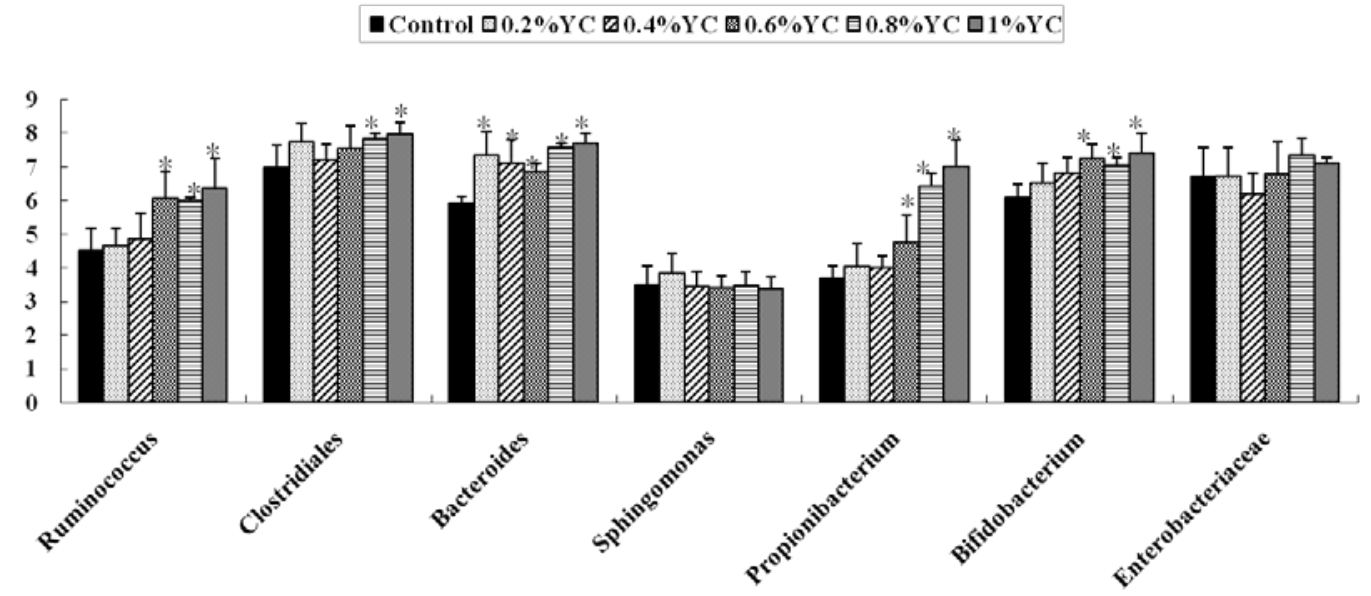

b.

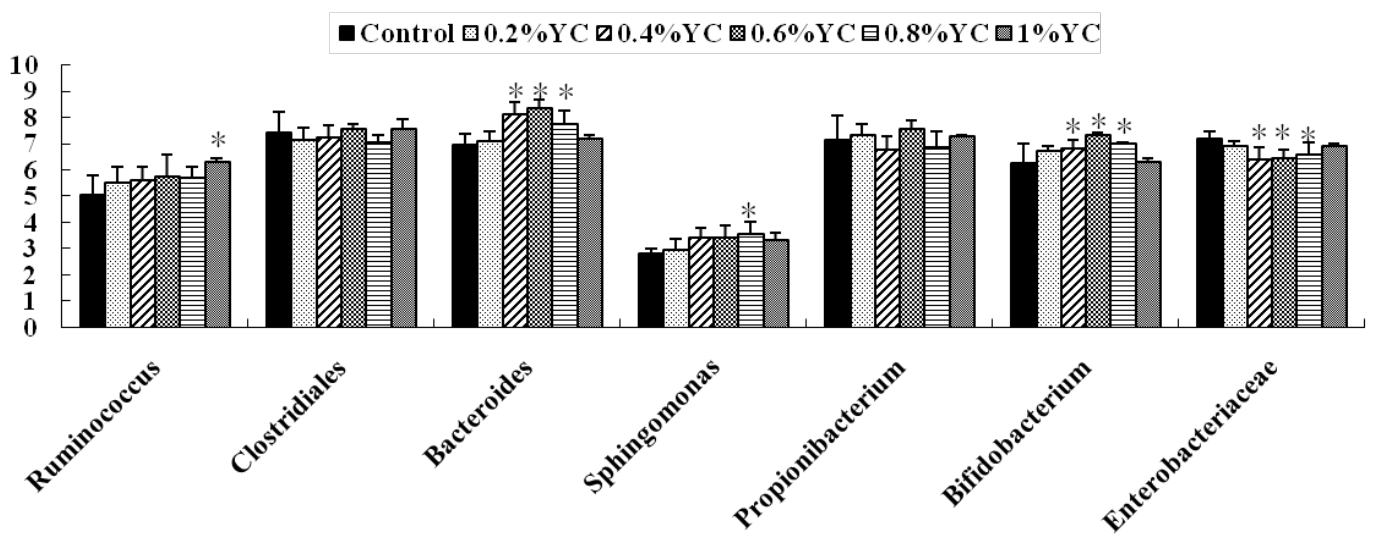

Figure 3 The gene copy number [lg(copies $g-1)]$ of bacteria when supplemented with various levels of yeast culture $(\mathrm{YC})$ on days $21(\mathrm{a})$ and $42(\mathrm{~b})$

Values with asterisks $\left(^{*}\right)$ are significantly different $(P<0.05)$

Dietary supplementation of $0.8 \% \mathrm{YC}$ improved the apparent total tract digestibility of $\mathrm{EE}, \mathrm{Ca}$ and $\mathrm{P}$. This could be attributed to the higher activity of phytase in the YC, thereby leading to the decomposition of organophosphorus in the feed. However, YC showed no significant effect on the digestibility of CP, which is similar to the results of Kornegay et al. (1995) and Gao et al. (2008).

Only a limited number of caecal bacterial species have been successfully cultured in vitro (Salanitro et al., 1974; Rolfe, 2000) because optimal culture conditions have not been established, whereas PCR-DGGE can reliably detect changes in intestinal flora. The present study revealed significant differences in the caecal bacteria community structure among various YC dietary supplementation groups. The caecal microbiota is diverse and $1 \mathrm{~g}$ (wet weight) of caecal content may contain $1 \times 1011$ bacteria (Mead et al., 1997), and the bacteria belong to several bacterial phyla. Choi et al. (2014) observed that the predominant bacterial phyla in the gut microbiota consist of Firmicutes, and the major bacterial phyluminclude Bacteroidetes, Proteobacteria and Actinobacteria, which agree with the results of the current study. The bacterial flora in chickens such as Lactobacillus, Bifidobacterium and Colibacillus has been successfully cultured. However, the sequence of Lactobacillus was not detected. This suggests that PCR-DGGE may have limitations, including DNA extraction, amplification and cloning (Farrelly et al., 1995; Zhu et al., 2002).

The composition of the caecal bacteria community remained the same despite supplementation with various levels of YC. This indicates that some microorganisms are essential for the growth of the host, and the existence of microorganisms is not easily affected by the rearing environment or changes in diet, although quantity may be affected. However, some predominant strains in the YC groups might have been affected by changes in diet. The predominant bacteria included Rikenella sp., Alistipes sp. and Stomatobaculum longum gen. nov., sp. nov were observed in the $0.8 \%$ YC group on day 42. Rikenella sp. and Alistipes sp. belong to the 
bacteroidetes cluster, and Stomatobaculum longum gen. nov.,sp. nov belongs to the Firmicute group (Sizova et al., 2013).

In the current study, the density of beneficial bacteria such as Ruminococcus, Clostridiales, Bacteroides, Propionibacterium and Bifidobacterium increased in the YC groups. Ruminococcus, and Clostridiales belong to the Firmicute family, and Bäckhed et al. (2004) demonstrated that Firmicute and Bacteroidetes promote the deposition of fat. The apparent total tract digestibility of EE increased in the YC groups, which may be due to the increase in the density of Ruminococcus, Clostridiales and Bacteroides, whereas dietary supplementation with YC decreased Enterobacteriaceae quantity on day 42. Previous studies involving chickens and pigs obtained similar results (Kogan \& Kocher, 2007; Cai et al., 2015). These results could be attributed to the mannose and glucans of the yeast cell wall (Oyofo et al., 1989) as mannose can modify microflora fermentation to favour nutrient availability to the host and agglutinate Escherichia coli and Salmonella, thus removing pathogens from the intestinal wall (Spring et al., 2000; Bovera et al., 2012). Tian et al. (2015) showed that yeast $\beta$-glucans supplementation benefited the gut ecosystem by increasing the density of Lactobacillus and Bifidobacterium. Furthermore, Lactobacillus and Bifidobacterium have beneficial effects on broiler performance (Mountzouris et al., 2007).

\section{Conclusion}

The present study certified that dietary supplementation with $0.8 \%$ YC increased feed efficiency, and apparent digestibility of ether extract, calcium and phosphorus, as well as positively changed the caecal bacterial density and diversity in broiler chickens.

\section{Acknowledgments}

The Jilin Province Science and Technology Transformative Project (20160301003NY), the Jilin Science and Technology Development Plan-Science and Technology Innovation Centre Project (20170623075TC), and the Youth Talent Support Program of Jilin Agricultural University (2016005) supported this study.

\section{Authors' Contributions}

YGZ and TW conceived and designed the experiments. YGZ, WZ, CW and LJL performed the experiments. YGZ analysed the data. HGL and XFZ contributed reagents, materials, and analytical tools. YGZ and TW wrote the paper. HGL and TW edited the manuscript.

\section{Conflict of Interest Declaration}

The authors declare that they have no conflict of interest.

\section{References}

Abdelrahman, M.M., 2013. Effect of feeding dry fat and yeast culture on broiler chicken performance. Turk. J. Vet. Anim. Sci. 37, 31-37.

AOAC International., 2005. Official methods of analysis of AOAC International.AOAC International. 18th Edition, Association of Official Analytical Chemist, Washington DC., USA.

Bäckhed, F., Ding, H., Wang, T., Hooper, L.V., Koh, G.Y., Nagy, A. \& Gordon, J.I., 2004. The gut microbiota as an environmental factor that regulates fat storage. P. Natl. Acad. Sci. USA. 101, 15718-15723.

Bovera, F., Lestingi, A., Iannaccone, F., Tateo, A. \& Nizza, A., 2012. Use of dietary mannanoligosaccharides during rabbit fattening period: Effects on growth performance, feed nutrient digestibility, carcass traits, and meat quality. J. Anim. Sci. 90, 3858-3866.

Cai, L., Park, Y.S., Seong, S.I., Yoo, S.W. \& Kim, I.H., 2015. Effects of rare earth elements-enriched yeast on growth performance, nutrient digestibility, meat quality, relative organ weight, and excreta microflora in broiler chickens. Livest. Sci. 172, 43-49.

Chand, N., Ihsanudin \& Khan, R.U., 2014. Replacement of soybean meal with yeast single cell protein in broiler ration: the effect on performance traits. Pak. J. Zool. 46 (6), 1753-1758.

Choi, J.H., Kim, G.B. \& Cha, C.J., 2014.Spatial heterogeneity and stability of bacterial community in the gastrointestinal tracts of broiler chickens. Poult. Sci. 93, 1942-1950.

Coci, M., Nicol, G.W., Pilloni, G.N., Schmid, M., Kamst-van Agterveld, M.P., Bodelier, P.L.E. \& Laanbroek, H.J., 2010. Quantitative assessment of ammonia-oxidizing bacterial communities in the epiphyton of submerged macrophytes in shallow lakes. Appl. Environ. Microb. 76, 1813-1821.

Farrelly, V., Rainey, F.A. \& Stackebrandt, E., 1995. Effect of genome size and rrn gene copy number on PCR amplification of 16S rRNA genes from a mixture of bacterial species. Appl. Environ. Microb. 61, 2798-2801.

Farthing, M.J.G., 1985. Intestinal microbiology. Gut 26, 1273-1274.

Gao, J., Zhang, H.J., Yu, S.H., Wu, S.G., Yoon, I., Quigley, J. \& Qi, G.H., 2008. Effects of yeast culture in broiler diets on performance and immunomodulatory functions. Poult. Sci. 87, 1377-1384.

Haldar, S., Ghosh, T.K. \& Bedford, M.R., 2011. Effects of yeast (Saccharomyces cerevisiae) and yeast protein concentrate on production performance of broiler chickens exposed to heat stress and challenged with Salmonella enteritidis. Anim. Feed Sci. Technol. 168, 61-71. 
Johansen, C.H., Bjerrum, L., Finster, K. \& Pedersen, K., 2006. Effects of a Campylobacter jejuni infection on the development of the intestinal microflora of broiler chickens. Poult. Sci. 85, 579-587.

Kogan, G. \& Kocher, A., 2007. Role of yeast cell wall polysaccharides in pig nutrition and health protection. Livest. Sci. 109, 161-165

Kornegay, E.T., Rhein-Welker, D., Lindemann, M.D. \& Wood, C.M., 1995. Performance and nutrient digestibility in weanling pigs as influenced by yeast culture additions to starter diets containing dried whey or one of two fiber sources. J. Anim. Sci. 73, 1381-1389.

Mead, G.C., 1997., Bacteria in the gastrointestinal tract of birds. In: Gastrointestinal microbiology. Chapman \& Hall Microbiology Series, New York. pp. 216-240.

Mountzouris, K.C., Tsirtsikos, P., Kalamara, E., Nitsch, S., Schatzmayr, G. \& Fegeros, K., 2007. Evaluation of the efficacy of a probiotic containing Lactobacillus, Bifidobacterium, Enterococcus, and Pediococcus strains in promoting broiler performance and modulating cecal microflora composition and metabolic activities. Poult. Sci. 86, 309-317.

NY/T2666-2014, 2015., Announcement No.2166 of the Ministry of Agriculture of People's Republic of China Standardized breeding farm for broiler chicken.

Oyofo, B.A., DeLoach, J.R., Corrier, D.E., Norman, J.O., Ziprin, R.L. \& Mollenhauer, H.H., 1989. Prevention of Salmonella typhimurium colonization of broilers with D-mannose. Poult. Sci. 68, 1357-1360.

Reisinger, N., Ganner, A., Masching, S., Schatzmayr, G. \& Applegate, T.J., 2012.Efficacy of a yeast derivative on broiler performance, intestinal morphology and blood profile. Livest. Sci. 143, 195-200.

Rolfe, R.D., 2000. The role of probiotic cultures in the control of gastrointestinal health. J. Nutr. 130, 396S-402S.

Salanitro, J.P., Blake, I.G. \& Muirhead P.A., 1974. Studies on the cecal microflora of commercial broiler chickens. J. Appl. Microbiol. 28, 439-447.

Shen, Y.B., Piao, X.S., Kim, S.W., Wang, L., Liu, P., Yoon, I. \& Zhen, Y.G., 2009. Effects of yeast culture supplementation on growth performance, intestinal health, and immune response of nursery pigs. J. Anim. Sci. 87, 2614-2624.

Sizova, M.V., Muller, P., Panikov, N., Mandalakis, M., Hohmann, T., Hazen, A. \& Epstein, S.S., 2013.Stomatobaculum longum gen. nov.,sp. nov., an obligately anaerobic bacterium from the human oral cavity. Int. J. Syst. Evol. Mic. 63, 1450-1456.

Spring, P., Wenk, C., Dawson, K.A. \& Newman, K.E., 2000. The effects of dietary mannaoligosaccharides on cecal parameters and the concentrations of enteric bacteria in the ceca of salmonella-challenged broiler chicks. Poult. Sci. 79, 205-211.

Sultan, A., Uddin, I., Khan, S., Ullah, R., Khan, H., Khan, N.A. \& Khan, R.U., 2015. Effect of yeast derived carbohydrate fraction on growth performance, apparent metabolizable energy, mineral retention and gut histomorphology of broilers during starter phase. Pak. Vet. J. 35 (4), 409-413.

Swinkels, W.J.C., Post, J., Cornelissen, J.B., Engel, B., Boersma, W.J.A. \& Rebel, J.M.J., 2006. Immune responses in Eimeriaacervulina infected one-day-old broilers compared to amount of Eimeria in the duodenum, measured by real-time PCR. Vet. Parasitol. 138, 223-233.

Tian, X., Shao, Y., Wang, Z. \& Guo, Y., 2016. Effects of dietary yeast $\beta$-glucans supplementation on growth performance, gut morphology, intestinal Clostridium perfringens population and immune response of broiler chickens challenged with necrotic enteritis. Anim. Feed Sci. Technol. 215, 144-155.

Yu, Z. \& Morrison, M., 2004. Comparisons of different hypervariable regions of rrs genes for use in fingerprinting of microbial communities by PCR-denaturing gradient gel electrophoresis. Appl. Environ. Microb. 70, 4800-4806.

Zhang, A.W., Lee, B.D., Lee, S.K., Lee, K.W., An, G.H., Song, K.B. \& Lee, C.H., 2005. Effects of yeast (Saccharomyces cerevisiae) cell components on growth performance, meat quality,and ileal mucosa development of broiler chicks. Poult. Sci. 84, 1015-1021.

Zhu, X.Y., Zhong, T., Pandya, Y. \& Joerger, R.D., 2002. 16S rRNA-based analysis of microbiota from the cecum of broiler chickens. Appl. Environ. Microb. 68, 124-137. 